\title{
Games e interatividade: mapeando possibilidades
}

\section{Games and interactivity: map possibilities}

\section{Lynn Alves}

Pós-doutorado em Jogos eletrônicos e aprendizagem pela Universidade de Turim, professora Titular do Programa de Pós-graduação em Educação e Contemporaneidade UNEB, Professora do Programa de Pós-Graduação em Modelagem Computacional SENAI - CIMATEC.

Iynnalves@gmail.com

\section{Abstract}

This article discusses the concept of interactivity and the expansion of opportunities for interaction in the game universe, highlighting the emergence of the participatory culture in which gamers stop playing just to interfere in aspects of logic and aesthetics of the game. Finally, we present the experience still preliminary game Guardians of the Forest that is creating a community of students and teachers to participate in and interfere with the game's narrative, acting as prosumer.

\section{Keywords}

Games, modification, collective intelligence, interactivity

\section{INTERATIVIDADE: CONSIDERAÇÕES INICIAIS}

Na teoria da comunicação, o aparecimento do termo interatividade se deu no início do século XX. Em 1932, Brecht, citado por Machado (1997), já se referia à interatividade quanto à possibilidade que os rádios traziam para uma interação comunicacional mais livre. Mas foi em finais dos anos 60, a partir do desenvolvimento da semiologia e da semiótica, que o conceito começou a ser mais difundido e relacionado mais diretamente às tecnologias eletrônicas. A interatividade passa a ser concebida como um processo de permuta contínua das funções de emissão e recepção comunicativa. Muitos artistas, comunicólogos, engenheiros eletrônicos começam a desenvolver projetos no sentido de criar produtos cujos resultados semióticos derivariam de uma intervenção direta dos emissores e receptores. Uma obra que nunca estaria pronta: seu conteúdo só se concretizaria no momento de sua atualização, de interação do emissor e receptor que, nesse sentido, se constituiria num co- 
autor desse produto. No Brasil, a obra tropicalista de Lygia Clark, Hélio Oiticica é um exemplo significativo dessa concepção (Silva, 2000, p. 59).

Por conseguinte, a interatividade se constitui na pedra de toque das novas mídias. A maleabilidade e reflexibilidade dos bits, assim como a rapidez nas consultas e respostas dos seus sistemas, propiciam condições técnicas infraestruturais para uma comunicação muito mais interativa do que as experiências anteriores. Acrescenta-se a isso uma possibilidade de interação simultânea de um número muito maior de comunicantes.

Assim, muda-se o caráter da interatividade, devido a razões quantitativas (número de pessoas interagindo) e qualitativas (variedade, riqueza e natureza das interações) (Machado, 1997, p. 147). A interatividade passa então a levar em consideração a possibilidade de imersão, navegação, exploração e conversação presentes nos suportes de comunicação em rede, privilegiando um visual enriquecido e "recorporalizado", em contraponto a um visual retiniano (linear e seqüencial), que recompõe uma outra hierarquia do sensível (Couchot, 1997, p.139), instaurando, assim, uma lógica que rompe com a linearidade, com a hierarquia, para dar lugar a uma lógica heterárquica, rizomática, hipertextual.

Teríamos a possibilidade de alcançar aquilo que Lèvy denominou de terceiro nível de interatividade, não mais do tipo Um - Todos, nem Um - Um, mas do tipo Todos - Todos (1994, p. 50), em que os sujeitos podem trocar, negociar e intercambiar diferentes saberes ao mesmo tempo.

Portanto, a interatividade passa ser compreendida como a possibilidade de o usuário participar ativamente, interferindo no processo com ações, reações, intervenções, tornando-se receptor e emissor de mensagens que ganham plasticidade, permitem a transformação imediata (Lèvy,1999, p. 60), criam novos caminhos, trilhas, cartografias, valendo-se do desejo do sujeito. Acrescenta-se também a capacidade desses novos sistemas de acolher as necessidades do usuário e satisfazê-lo (Battetini, 1996, p. 67).

Nessa perspectiva, os produtos e, em especial, os games não mais "chegariam" prontos ao destinatário. A este caberia o desafio de remodelar, ressignificar e transformar o produto com o qual estivesse interagindo, de acordo com sua imaginação, necessidade ou desejo - obviamente, dentro dos limites técnicos dos suportes. Isso abre maiores chances para que os discursos se tornem mais abertos e fluídos, o que diminui bastante as fronteiras e 
distâncias existentes no processo de comunicação entre emissores e receptores, sem que, com isso, os agentes produtores percam a sua singularidade. É a própria escrita do mundo, confundida com sua leitura, que tende a se tornar coletiva e anônima.

Assim, a textualidade produzida pelos discursos não pode "ser considerada um sistema fechado de signos: ela é sempre uma ação em devir (in fieri)". (Battetini, 1996, p.69).

O fato de as informações estarem dispostas em redes digitais acaba elevando o grau de metamorfose constante dos produtos e saberes, o que dificulta a cristalização de ideias, conceitos e estéticas. Isso implica na ampliação do caráter coletivo do saber, fruto da viabilidade da troca dinâmica e instantânea de saberes singulares de um grande número de agentes produtivos. Por sua vez, torna possível que muitos sejam, ao mesmo tempo, produtores, difusores e consumidores de discursos, viabiliza as condições para a concretização de uma situação, na qual não existiriam mais centros exclusivos de produção, descaracterizando (ao menos parcialmente), assim, o chamado "consumo de massa". Nesse sentido, o próprio saber poderia se transformar num grande hipertexto, construído e reconstruído, por milhares de mãos e cérebros, sem eixos centrais. Algumas características técnicas desses novos dispositivos permitem ainda uma utilização mais constante e criativa de lógicas hipertextuais e não-lineares.

Embora a hipertextualidade não tenha sido criada pelas tecnologias digitais e telemáticas, visto que ela pertence à própria forma de raciocínio dos homens, estas aumentam significativamente as possibilidades de sua utilização no processo de produção cultural e acadêmica e no de armazenamento e consulta de fontes e dados por parte dos usuários.

A hipertextualidade é aqui compreendida na perspectiva de Lèvy, como uma imensa rede associativa que constitui nosso universo mental e encontrase em metamorfose permanente. As reorganizações podem ser temporárias e superficiais quando, por exemplo, desviamos momentaneamente o núcleo de nossa atenção para a audição de um discurso, ou profundas e permanentes como nos casos em que dizemos que 'a vida' ou 'uma longa experiência' nos ensinaram alguma coisa. (1993, p. 24). 
Logo, os saberes e as informações passam, então, a serem dispostos de forma associativa na rede ao qual pertencem, modificando a lógica de acesso aos mesmos.

Hoje, podemos encontrar esse tipo de interatividade aplicada facilmente em algumas tecnologias síncronas, como nos softwares de comunicação instantânea, na videoconferência, nos jogos de RPG ${ }^{1}$ e nos Muds ${ }^{2}$, mas ainda não muito desenvolvidas em larga escala, devido a alguns problemas técnicos momentâneos e aos preconceitos e barreiras culturais colocadas no mundo do conhecimento, visto que esse processo toca em questões ainda controvertidas, a exemplo da problemática autoral ${ }^{3}$. Mas muitos avanços vêm sendo conquistados no universo da arte tecnológica e de áreas de pesquisa específicas, como a robótica e a realidade virtual. Entretanto, ainda são, em certo sentido, limitados, devido a problemas de velocidade de transmissão de dados numa rede como a Internet.

No que se refere à interatividade dos games, percebe-se um avanço significativo nesses elementos tecnológicos. Lèvy descreve estas potencialidades:

No videogame, cada jogador, ao agir sobre o joystick, dataglove ou outros controles, modifica em um primeiro tempo sua imagem no espaço do jogo. O personagem vai evitar um projétil, avançar rumo a seu objetivo, explorar uma passagem, ganhar ou perder armas, "poderes", "vidas" etc. É essa imagem modificada do personagem reatualizado que modifica, em um segundo tempo lógico, o próprio espaço do jogo. Para envolver-se de verdade, o jogador deve projetar-se no personagem que o

\footnotetext{
${ }^{1}$ Roleplaying games - Jogo de tabuleiro que surgiu na década de setenta nos Estados Unidos, no qual o participante vive uma história sem ter de obedecer a uma posição apenas passiva, sendo parte ator, parte roteirista de um texto que ainda não foi completamente escrito. As regras se constituem em um apoio e podem, ou não, ser utilizadas; não há ganhadores: todos se divertem e todos ganham. Este tipo de jogo vem sendo adaptado para a WEB. PAVAO, Andréa. A aventura da leitura e da escrita entre mestres de role-playing games. São Paulo: Devir, 2000.

${ }^{2}$ São jogos on line, nos quais os participantes podem construir diferentes personagens, atuando no mundo virtual, exercendo o poder da palavra por meio do teclado. TURKLE, Sherry. A vida no ecrã - a identidade na era da Internet. Lisboa: Relógio D'água, 1997. MURRAY, Janet H. Hamlet em la holocubierta - el futuro de la narrativa em el ciberespacio. Barcelona: Paidós, 1999.

${ }^{3}$ Vale a pena citar que, atualmente, existem experiências que permitem ao leitor interagir com o livro, inclusive dando feedback aos autores. Softwares como o Kobo por exemplo, permitem que os seus usuários possam criar uma rede social para comentar e discutir o que estão lendo, fazer comentários de determinados trechos do livro, além de permitir que os autores acompanhem esse processo de imersão no universo da leitura dos livros virtuais.

No início dos anos 2000 o autor Mário Prata escreveu o livro "Anjos de Badaró" on-line; nele, os internautas acompanharam a elaboração de cada parágrafo do romance. Na medida que os leitores internautas faziam contribuições, o autor realizava modificações no texto. Esta experiência pode ser considerada no Brasil, um marco do aparecimento de sistemas de criação de textos escritos coletivamente.
} 
representa e, portanto, ao mesmo tempo, no campo de ameaças, forcas e oportunidades em que vive no mundo virtual comum. A cada "golpe", o jogador envia ao seu parceiro uma outra imagem de si mesmo e de seu mundo comum, imagens que o parceiro recebe diretamente (ou pode descobrir explorando) e que o afetam imediatamente. A mensagem é a imagem dupla da situação e do jogador (1999, p.80).

Avançando nessa perspectiva pontuada por Lèvy há mais de dez anos atrás percebemos nos distintos consoles, a exemplo do Xbox com o Kinect, o move para o PS3 um potencial tecnológico mais interativo já que possibilitam aos jogadores experiências sinestésicas significativas, mobilizando todo o corpo além de permitir práticas colaborativas mediadas pela imersão no universo dos jogos.

A interatividade também está presente nos diferentes tipos de RPG. Nos jogos de tabuleiro, as condições de jogada são pré-definidas por um espaço delimitado, onde os jogadores têm que seguir os caminhos propostos pela estrutura do game. Logo, apresentam um nível de interatividade mais baixo em relação às diferentes modalidades dos jogos de RPG, como os de cartas, GURPS e Live Action. Neste último, o sujeito interage de forma bem mais ativa, dramatizando as situações inclusive, o que eleva a participação afetiva e sensório-motora. Para Murray, a atuação vai além da participação e da atividade e envolve a alteração dinâmica, na qual as narrativas vão se constituindo no processo:

A forma mais ativa de implicação dos sujeitos se dá nos jogos de RPG. Os fãs da literatura de aventura, desde Tolkien até as séries do espaço, se encontram para jogar o Live Action em que interpretam os personagens baseados nas histórias originais e jogam em um mesmo universo fictício (1999, p.53).

Dessa forma, a autora atribui ao RPG um nível muito elevado de interatividade. Dentro do sistema GURPS - Vampiro, os jogadores imergem em um mundo repleto por Clãs que disputam constantemente o poder, exigindo o desenvolvimento de habilidades e estratégias para se manter vivo.

A dinâmica do jogo consiste na leitura do livro de regras 
que em geral é lido pelo mestre que, nas sessões de RPG então, apresenta uma história, uma aventura, ao grupo de jogadores, criada por ele, a partir da leitura original. A aventura proposta deve conter enigmas, charadas e situações que exigirão escolhas por parte dos jogadores. Cada participante, tal como um autor de ficção, constrói um personagem para si, detalhando seu perfil psicológico, suas habilidades intelectuais e físicas, suas preferências e seus trunfos, assim como suas deficiências, que vão garantir o "tempero" da ficção. Esses personagens devem adequar-se a um ambiente, proposto pelo livro do mestre, no qual a trama se desenrolará. O ambiente onde se desenvolve a aventura, no linguajar desses grupos, é chamado de mundo ou cenário (Pavão, 2000, p.18-19).

Além da leitura, alguns Mestres de RPG também escrevem um texto introdutório para situar os players ${ }^{4}$ no roteiro criado e, assim, iniciam a aventura. E, como aponta Pavão:

Há também notícias de mestres que escrevem contos a partir da aventura desenvolvida com a participação dos players. Os autores de RPG são em geral mestres que, insatisfeitos com os sistemas de jogo oferecidos no mercado, decidiram criar seu próprio sistema de jogo (Pavão, 2000, p.20).

Outra possibilidade de jogar RPG é através da WEB, com a utilização do teclado ou o bate papo. Na perspectiva de Murray, a realização dos jogos do tipo RPG e MUD, nestes ambientes, podem contribuir para a constituição de um grande grupo de teatro mundial:

O computador nos proporciona um novo cenário para o teatro participativo. Estamos aprendendo pouco a pouco a fazer o que fazem os atores: a representar emoções autênticas que sabemos que não são "reais". Quanto mais persuasiva for a representação sensorial do espaço digital, mais presentes nos sentiremos no mundo virtual, e, portanto, seremos capazes de realizar muito mais ações. A facilidade com que os jogadores de MUD e RPG adaptam personagens sugere que há um grupo crescente capaz de representar outros papéis. Pouco a pouco, nós estamos nos convertendo em um grupo de teatro mundial, que pode adaptar papéis em histórias participativas cada vez mais complexas. Estamos iniciando a descoberta das convenções participativas que

\footnotetext{
${ }^{4}$ Jogadores de RPG.
} 
definiram a quarta parede do teatro virtual: os gestos expressivos que enriqueceram e preservaram o encantamento da imersão (1999, p.138).

A rede, portanto, potencializa a interatividade e o nível de participação dos RPGs, criando ambientes que se transformam em verdadeiros filmes interativos, construídos a partir da participação de inúmeros interatores.

A possibilidade de criar caminhos e cenários inexistentes, nos quais o jogador utiliza os conteúdos que permeiam o seu imaginário para construir narrativas que não estão pré-definidas, caracteriza a interatividade, o que potencializa a imersão em um universo de histórias, em que o player ocupa o papel de interator.

Em contraponto à riqueza de narrativa dos jogos de RPG do tipo Live Action, estão os games. Para Turkle (1989, p. 71), nos games, as regras são definidas previamente e, para modificá-las, temos que entrar no mundo dos programadores que o criaram. No mundo dos games, existem muitas possibilidades, mas estas são finitas, diferente dos MUDS e RPGs, nos quais o desempenho de um papel tem sempre um final em aberto. Portanto, nos jogos de papéis, como no RPG, é possível imergir, experienciar e se transportar psicologicamente para um lugar que exige toda a nossa atenção e concentração com relação aos nossos sentidos. E, nesse processo, o que diverte é o

[...] movimento fora de nosso mundo habitual, surgindo à sensação de alerta quando se está em um lugar novo, e o prazer de aprender a se mover lá. A imersão pode levar a mente a se inundar de sensações e estimulação sensorial (Murray, 1999, p.111).

O autor Levis (1997, p. 36) discute também a interatividade dos jogos eletrônicos, ao registrar que os sistemas interativos apresentam dois aspectos. $O$ primeiro se refere à possibilidade de atuação do usuário sobre o desenvolvimento da mensagem emitida pelo programa; o segundo se relaciona ao volume de informações que o sistema maneja. Portanto, são considerados interativos os programas que possibilitam uma maior abertura ao usuário. Dentro desta concepção, ele prevê que a evolução dos videogames pode potencializar o nascimento de uma nova linguagem cinemática interativa, que pode definir as formas da ficção do futuro.

Indo além da discussão da interatividade, Jenkins (2008) nos apresenta o conceito de cultura participativa. Nesta cultura rompe-se a dicotomia 
consumidores e produtores na medida em que os interatores podem atuar como produtores de conteúdos. Esta prática já vem acontecendo nas comunidades de fanfictions (grupo que através das interfaces comunicacionais, criam ficções usando personagens e universos dos conteúdos midiáticos. Por exemplo, fóruns, blog para discutirem, construírem e reconstruírem as narrativas sobre determinada obra, como por exemplo, Harry Porter) e as empresas que produzem e distribuem os discursos midiáticos, já que os fans ampliam os discursos relativos aos produtos e as empresas têm medo de perder o controle e os direitos autorais das suas obras (refiro-me aos jogos eletrônicos, livros, filmes, animações, etc).

Mas o que fazem esses fans? Produzem conteúdos que envolvem a elaboração de textos, de imagens, entre outras linguagens que exigem leituras prévias e interação com os produtos que os fascina. Além disto, exercitam competências gerenciais na medida em que: a) organizam as comunidades que são formadas por outras pessoas que estão muitas vezes do outro lado do mapa; b) produzem as informações e c) sistematizam dados. Estes sujeitos estão imersos em um processo sócio-cultural no qual os pares atuam como interventores na zona de desenvolvimento proximal (Vygotsky, 1994) dos seus parceiros.

Essa possibilidade de modificação também está presente nos games, permitindo que através de ferramentas o jogador possa fazer alterações nos mapas, nos avatares, customizando para garantir maior nível de participação dos gamers.

Mod vem do termo modification que são modificações feitas pelos fãs que criam cenários e modalidades baseados na tecnologia de um jogo.

A criação dos mapas, skins (peles) e armas não é algo novo. Como já dito anteriormente, essa possibilidade de modificar o ambiente do jogo começou com o Quake, quando a ID Software, produtora do jogo, oferecia ferramentas para a criação. Esta idéia vem sendo hoje desenvolvida por quase todos os jogos em primeira pessoa ${ }^{5}$, com o objetivo de estimular a criatividade dos usuários. O jogo Counter Strike (CS) é uma modificação (Mod) do jogo Half-

\footnotetext{
${ }^{5} \mathrm{O}$ estilo de jogos em primeira pessoa foi uma perspectiva revolucionária na história dos games e foi iniciado pela ID, em maio de 1992, com o lançamento de Wolfenstein 3-D, surgindo, posteriormente, jogos como: Doom (1993), Quake (1996), Half Life, Half-Life e Thief - The Dark Project (1998), Unreal Tournament (1999), e No One Lives Forever e Project IGI: I'm Going In. e Country Strike (2000), dentre outros.
} 
Life $(H L)$, criado por Minh Le e Jess Cliffe no qual o jogador pode criar seus mapas com editores gráficos disponibilizados na Internet. Este caso é o mais citado como sucesso comercial surgido a partir da comunidade de modders, no início dos anos 2000.

Outro jogo é o WorldCraft, desenvolvido pela Valve no qual os modders podem criar as paredes dos cenários, por exemplo. O Rage e The Sims nos quais o jogador pode alterar os mapas originais, disponibilizando inclusive para comunidade.

Considerando a complexidade dessa ação que muitas vezes pode exigir tempo e conhecimento de softwares gráficos e de modelagem 3D, as desenvolvedoras de games, já disponibilizam ferramentas que permitem ao jogador, modders amadores programar níveis ou universos adicionais que possam estender suas experiências no jogo (Jenkins, 2008).

Desta forma, muitas empresas da área de games, a exemplo da Maxis, estabelece uma interlocução com a comunidade de gamers que criam e produzem as modificações retroalimentando o processo de desenvolvimento dos seus produtos, possibilitando que seus consumidores ultrapassem o linha de meros receptores para produtores de conteúdos.

A participação nestas redes de colaboração onde os jogadores criam e socializam suas produções, delineia a emergência de uma inteligência coletiva que para Lèvy (1996) se constrói em tempo real, baseada em três aforismas: ninguém sabe tudo; cada um tem um saber; e todo o saber está disponibilizado na humanidade.

\subsection{Guardiões da Floresta - uma experiência interativa}

O Grupo de Pesquisa Comunidades Virtuais da Universidade do Estado da Bahia - UNEB, foi criado em 2002 e desde 2006 vem desenvolvendo jogos voltados para distintos cenários de aprendizagem. Atualmente o grupo tem no seu portfolium nove jogos desenvolvidos e três em processo de desenvolvimento.

Um dos jogos desenvolvido pelo grupo foi o jogo Guardiões da Floresta - GDF, produzido em Flash, em $2 \mathrm{D}$, single play, no estilo adventure, para os sistemas operacionais Windows e Linux, para crianças na faixa etária de 08 a 12 anos. 
A narrativa do jogo trata de questões relacionadas com a preservação da fauna e flora no cenário da Floresta Amazônica. O jogo desafia o jogador a salvar a floresta do desmatamento feito por uma fábrica de celulose. Para realizar a missão é necessário solucionar cinco mini-games que visam desenvolver conceitos relacionados com: o Sistema de Numeração Decimal, relações projetivas no espaço, localização espacial e problema aberto.

As crianças e professores do ensino fundamental I (do 10. ao 5o. ano) são desafiados a interagir com o jogo e posteriormente a (re)construir e ampliar a narrativa inicial, utilizando diferentes linguagens, a exemplo da História em Quadrinho, textos imagéticos e escritos e até a produção de novos games utilizando o software Scracht.

Estas produções estarão disponíveis no site do jogo, possibilitando que os jogadores atuem como produtores de conteúdos relacionados com a narrativa do GDF .

A pesquisa vem sendo realizada na Escola Municipal Maria Conceição Imbassay, com crianças na faixa etária de 09 a 13 anos e com os alunos do curso de pedagogia da UNEB - Campus Salvador. A nossa intenção é envolver a comunidade no processo de produção do jogo, possibilitando uma atuação mais interativa do processo. As contribuições destes sujeitos irão subsidiar o desenvolvimento do Gamebook que terá o mesmo tema do jogo GDF, atentando para as indicações sugeridas pelos jogadores e professores.

Desta forma, estaremos viabilizando uma trajetória diferenciada de criar modificações nas novas versões do jogo tomando como referência a perspectiva dos sujeitos que irão construir sentidos para este artefato tecnológico.

A relação jogos digitais e interatividade vem sendo potencializada a cada dia, seja para exigência dos seus jogadores que não querem apenas imergir no universo das narrativas de forma lúdica, mas querem participar das suas produções e definições indicando para as grandes empresas aspectos relacionados com a jogabilidade e narrativas que mobilizam seus desejos e subjetividades.

Cabe a nós pesquisadores e desenvolvedores de games estar atentos a essas novas demandas, criando e fortalecendo esses espaços de intercâmbio de saberes que potencializam a inteligência coletiva tão defendida por teóricos como Lèvy (1996). 


\section{REFERÊNCIAS}

BATTETINI, G. (1996). Semiótica, computação gráfica e textualidade. PARENTE, A. (Org.). Imagem máquina - A era das tecnologias do virtual. Rio de Janeiro: Ed. 34, p. 65-71.

CAPUCCI. Luigi. (1997). Por uma arte do futuro. In: DOMINGUES. Diana (org). A arte no século XXI: a humanização das tecnologias. São Paulo: Fundação Editora da UNESP, p. 129-134

COUCHOT, Edmond. (1997) A arte pode ainda ser um relógio que adianta? O autor, a obra e o espectador na hora do tempo real. . In: DOMINGUES. Diana (org). A arte no século XXI: a humanização das tecnologias. São Paulo: Fundação Editora da UNESP, p. 135-143.

JENKINS, Henry. (2008). Cultura da convergência. São Paulo: Aleph

LEVIS, Diego. (1997). Los videojuegos, um fenômeno de masas: que impacto produce sobre la infância y la juventud la industria más próspera del sistema audiovisual. Barcelona: Paidós

LÈVY, Pierre. (1993). As tecnologias da inteligência - o futuro do pensamento na era da informática. Rio de Janeiro: Ed. 34.

LÈVY, Pierre. (1998) A inteligência coletiva - Para uma antropologia do ciberespaço. Cortez: São Paulo.

LÈVY, Pierre. (1996) O que é virtual? São Paulo: Ed. 34

LÈVY, Pierre. Cibercultura. (1999). Rio de Janeiro: Ed. 34

MACHADO, Arlindo. (2002). Regimes de Imersão e Modos de Agenciamento. In: INTERCOM - Sociedade Brasileira de Estudos Interdisciplinares da Comunicação XXV Congresso Brasileiro de Ciências da Comunicação Salvador/BA - 1 a 5 Set 2002.

MURRAY, Janet H. (1999). Hamlet em la holocubierta - el futuro de la narrativa em el ciberespacio. Barcelona: Paidós. 
PAVAO, Andréa. (2000). A aventura da leitura e da escrita entre mestres de role-playing games. São Paulo: Devir.

SILVA, Marcos. (2000). Sala de aula interativa. Rio de Janeiro: Quartet.

LÈVY, Pierre. (1997) A vida no ecrã - a identidade na era da Internet. Lisboa: Relógio D'água.

LÈVY, Pierre. (1989) O segundo EU - os computadores e o espírito humano. Lisboa: Presença.

VYGOTSKY, Lev Semynovitch. (1994) A formação Social da mente: o desenvolvimento dos processos psicológicos superiores. Org. Michael Cole...[et al.]; São Paulo, Martins Fontes. 